\title{
Quantitative Trait Loci Associated with Resistance to Gray Leaf Spot of Corn
}

\author{
M. J. Clements, J. W. Dudley, and D. G. White
}

Department of Crop Sciences, University of Illinois, Urbana 61801.

Accepted for publication 7 February 2000.

\begin{abstract}
Clements, M. J., Dudley, J. W., and White, D. G. 2000. Quantitative trait loci associated with resistance to gray leaf spot of corn. Phytopathology 90:1018-1025.

The susceptible parent FR1141, the resistant parent 061, the $\mathrm{F}_{1}$ cross, and 301 families selfed once from backcrosses to the susceptible parent were evaluated for gray leaf spot (GLS) severity for two years in Urbana, IL, and one year in Andrews, NC. Linkage between ear height and GLS severity was suspected. Therefore, plant height characteristics were noted for two years in Urbana, IL. Eighty-six polymorphic probes were

loci (QTL) associated with GLS, plant and ear height were determined. Five QTL were significantly associated with GLS resistance across all environments and rating periods. These five regions are associated with additive effects on phenotype and account for between 51.0 and $58.7 \%$ of the phenotypic variation associated with GLS severity. Additionally, six QTL were identified with maturity-dependent associations to GLS severity. Heritability of GLS resistance was estimated to be approximately 0.73 . Four QTL were identified with associations to ear height relative to total plant height. One of the four was associated with higher ear height and GLS resistance.
\end{abstract} used to construct a random fragment length polymorphism linkage map, and the presence, locations, effects, and interactions of quantitative trait
Additional keywords: Cercospora zeae-maydis, maize, molecular markers.
Since gray leaf spot (GLS) was described in 1925 (48), the disease has become firmly established as an economic problem in many of the corn growing regions of the United States and abroad $(20,33)$. The causal agent of GLS, Cercospora zeae-maydis Tehon and E. Y. Daniels (48), predominantly overwinters in previously diseased plant debris that remains unincorporated on the soil surface between seasons (40). Conidia produced by the fungus are disseminated to corn plants within and between fields by wind and rain splashing $(12,13,33)$. Development of the pathogen is favored by extended periods of high relative humidity $(>90 \%)(2,13,33$, 43,50). The most damaging epidemics of the disease occur when primary inoculum levels are high and infection takes place prior to anthesis $(2,26,33)$. Yield losses attributed to GLS have been variable (34), with estimated losses as high as $100 \%$ when severe epidemics contributed to increased stalk lodging and early senescence (33). Epidemics of gray leaf spot are frequently associated with the use of conservation tillage $(2,12,13,26,33,40,41,42,43)$, a practice now common throughout much of the southern and central United States. Host resistance is the most effective solution for GLS management. Abandonment of conservation tillage is neither economically nor environmentally sound and the application of chemical fungicides is rarely economical for grain production (53).

Due to the relatively recent increase in incidence and severity of GLS within the midwestern United States, germplasm used for corn hybrid development in this area has generally not been subjected to extended periods of selection for resistance. Most corn hybrids used in the Midwest prior to 1989 had a similar degree of susceptibility to gray leaf spot $(2,34)$. Recently, commercial hybrids with moderate levels of resistance have been marketed and used in the United States. Most of these hybrids do not have the high levels of resistance necessary to avoid loss

Corresponding author: M. J. Clements; E-mail address: mclement@ uiuc. edu

Publication no. P-2000-0720-03R

(c) 2000 The American Phytopathological Society during severe epidemics (34). Additionally, much of the germplasm identified as resistant has poor agronomic character-istics including low yield, late maturity, or susceptibility to other diseases $(7,10,15,20,21,26,49,51)$. This complicates breeding for resistance, as selection against these traits must be incorporated into breeding programs.

Manh (38) reported a relationship between hybrid maturity and GLS severity; observing that early maturing hybrids appeared to be more susceptible to GLS than late maturing hybrids. In a study of corn hybrids and inbreds in Tennessee, Hilty et al. (26) noted that initial disease symptoms coincided with silk emergence, and that the number of GLS lesions tended to increase as plants reached senescence. Rupe et al. (43) later observed that initial disease symptoms did not appear until plants were near anthesis, and that a three week delay in planting resulted in a three week delay in symptom appearance. Gwinn et al. (22) examined stomatal penetration by $C$. zeae-maydis in three cultivars of corn and concluded that age-dependent resistance mechanisms, which operate independently of varietal resistance, must exist. Seeking to quantify the relationship between host maturity and GLS severity, Bubeck et al. (7) recorded decreasing correlations between early and subsequently later disease ratings, concluding that early and late season resistance may involve different genes. Using generation mean analysis to study inheritance of resistance to GLS in three corn populations, Coates and White (11) supported this conclusion by observing that different forms of gene action were present in early and late season disease ratings.

Various sources of resistance have been studied to determine the inheritance of resistance to GLS. Based on the distribution of mean disease ratings in a study of the inbred Va14, Manh (38) reported that resistance to GLS is a quantitatively inherited trait. Using generation mean analysis, additive genetic effects accounted for 82 to $96 \%$ of the total variability among generations, although dominance and epistasis provided some contribution. Similar results were obtained by others using generation mean analysis $(11,49)$, diallel analysis $(2,13,15,20,27,49,51)$, and parent-progeny correlation (49). Collectively, these studies of various sources re- 
veal that resistance to GLS is (i) inherited additively; (ii) controlled by additive gene action, with possible minor dominant and epistatic contributions; (iii) associated with the general combining ability of inbred lines; and, (iv) controlled by few effective factors.

Though many studies have used restriction fragment length polymorphism (RFLP) technology to successfully identify chromosomal regions associated with quantitative traits in corn, only two have been published on the search for quantitative trait loci (QTL) associated with gray leaf spot resistance. In a study of three $\mathrm{F}_{2: 3}$ populations derived from crosses among resistant inbreds ADENT and NC250A with B73 and with B73rhml, Bubeck et al. (7) identified QTL associated with GLS resistance on each of the 10 corn chromosomes. The location of significant QTL was inconsistent over environments and populations. Only one region, near marker UMC131 on chromosome 2, was identified as being significantly (comparison-wise $P \leq 0.05$ ), associated with GLS resistance in all environments tested. Additive effects were significant for nearly all regions associated with resistance, while no epistatic and few dominance effects were observed.

Saghai-Maroof et al. (44) identified QTL associated with GLS resistance in a study of $\mathrm{F}_{2}$ and $\mathrm{F}_{2: 3}$ populations derived from the cross of Va14 $\times$ B73. This study identified nonenvironmentally influenced (i.e., environment-independent) marker-associated effects on chromosomes 1,4 , and 8 , and an additional environmentallydependent association on chromosome 2. The QTL alleles on chromosomes 1 and 2 were associated with additive gene action, whereas on chromosome 8 , alleles for resistance were recessive. The QTL alleles for resistance on chromosome 4 were partially dominant, with favorable alleles for resistance contributed by the susceptible B73 parent. This region on chromosome 4 was identified near probe UMC15, and also has been described by Bubeck et al. as being significantly associated with days after planting to silking (DAPS) (7).

Presently, gray leaf spot causes yield loss in some areas of the midwestern United States every year. Additional sources of resistance would be useful; particularly those that contribute to resistance of the B73-type inbred lines used to produce many Corn Belt hybrids (21). Previous objectives for GLS research at the University of Illinois have been to identify new sources of resistance and to determine the inheritance of that resistance. In the summer of 1989, 1,396 inbred corn lines were evaluated for resistance to GLS at Urbana, IL (10). From these lines, 62 inbreds were selected for further study based on disease reactions, lesion types, and maturities useful for breeding in central Illinois. In 1990, inbreds selected in 1989 and their $F_{1}$ crosses with FR1141, a GLS susceptible B73 recovery developed by Illinois Foundation Seeds, Inc (19), were evaluated for GLS resistance at Urbana, IL. Twenty-four of these lines were selected for further evaluation (10). Populations that included segregating generations were produced from crosses of these lines with susceptible inbreds FR1141 or FR20. These populations were evaluated for gray leaf spot resistance in 1991 at Urbana, IL, and three of the most resistant lines were selected for further study (9). The three lines selected in 1991 were crossed with FR1141 to produce segregating populations. Populations were evaluated in 1992 and 1993 at both Urbana, IL, and Andrews, NC, and the inheritance of resistance from the three selected lines was studied with generation mean analysis (11). One line, 061, was chosen for continued research at the University of Illinois. Inbred 061 is an agronomically poor, unreleased self out of PI320061. PI320061 was a population that was introduced to the United States from Brazil in May of 1967. Inbred 061 has been identified as having a high level of resistance to GLS (11) compared to other resistant inbreds B37HtN, DS:74:1071, CI30, Mo22, NC18, and T222. The high level of resistance contributed by 061 to B73-type inbred lines is highly heritable and transferred by backcrossing (11).

The objective of this study was to identify and characterize maturity- and environment-independent QTL associated with gray leaf spot resistance in the inbred line 061. An increase in ear height was observed as resistance from 061 was being crossed into B73-type inbreds using traditional breeding methods without the aid of molecular markers (White, unpublished data). Accordingly, plant and ear height were measured to determine if QTL associated with ear height relative to plant height were in close proximity to QTL associated with resistance. The information and materials from this project will add to the existing knowledge and germplasm of the commercial sector, support the continued use of conservation tillage, and improve the management of gray leaf spot.

\section{MATERIALS AND METHODS}

Plant materials. The susceptible parent FR1141 $\left(\mathrm{P}_{1}\right)$, the resistant parent $061\left(\mathrm{P}_{2}\right)$, the $\mathrm{F}_{1}$ cross, and 301 families selfed once from backcrosses to parent one $\left(\mathrm{BCP}_{1} \mathrm{~S}_{1}\right)\{[(\mathrm{FR} 1141 \times 061) \times$ FR1141] $\otimes$ \} were evaluated.

Field plots. The experiment was a randomized complete block design. Experimental units were families. For statistical analyses, year/location combinations were considered as environments. In each of three environments the experiment was divided into two blocks (replications), with one row (plot) each of 301 families $\left(\mathrm{BCP}_{1} \mathrm{~S}_{1}\right)$, and two rows each of the $\mathrm{P}_{1}, \mathrm{P}_{2}$, and $\mathrm{F}_{1}$ randomized within each block. Plots consisted of 24 kernels planted into $5.2 \mathrm{~m}$ rows (plus an alley of $\pm 0.5 \mathrm{~m}$ ) spaced $0.76 \mathrm{~m}$ apart. Plots in each environment were rated twice. Ratings were treated as repeated measures (45). Field plots were machine planted at the University of Illinois Crop Sciences Research and Education Center, Urbana, IL on 29 April, 1997 and 24 April, 1998. Plots also were machine planted on 6 May, 1998 at Andrews, NC by personnel of Pioneer Hi-bred International, Inc. Plots at Andrews, NC were not tilled, and seed was planted into corn residue from the previous season. Plots at Urbana, IL were chisel plowed in the fall preceding planting.

Inoculations. Gray leaf spot tends to develop late in the growing season in central Illinois. Therefore, plants at Urbana were inoculated and maintained under a low-output overhead-mist irrigation system to create conditions favorable for disease development (10). Plots at Andrews, NC were not inoculated due to high levels of naturally occurring GLS.

Differences in pathogenicity between isolates of C. zeae-maydis have been detected (3), therefore plants at Urbana, IL were inoculated with a mixture of 12 isolates in 1997 and 16 isolates in 1998. Isolates were obtained from the University of Illinois Plant Clinic and from grain production fields throughout Illinois. Isolates were maintained on V8 juice agar ( $300 \mathrm{ml}$ clarified V8 juice, $700 \mathrm{ml}$ de-ionized water, $20 \mathrm{~g}$ of agar per liter.) in $100 \times 15 \mathrm{~mm}$ petri plates. V8 was clarified by adding $8.82 \mathrm{~g}$ of $\mathrm{CaCO}_{3}$ per liter to $\mathrm{V} 8$ juice, autoclaving the mixture at $121^{\circ} \mathrm{C}$ for 20 minutes, cooling to room temperature and percolating by vacuum filtration through a $5 \mathrm{~cm}$ layer of diatomaceous earth over two filter paper disks in a $25 \mathrm{~cm}$ Büchner funnel. Clarified V8 juice was frozen until needed. Isolates were maintained by a method similar to that described by Huff et al. (27) except isolates were transferred to fresh media every 7 to 9 days. Isolates were incubated at approximately $25^{\circ} \mathrm{C}$ under $12 \mathrm{~h}$ of diurnal fluorescent lighting.

Inoculum was produced by blending one petri plate of each isolate with approximately $150 \mathrm{ml}$ of sterile, deionized water, and then spreading 2 to $3 \mathrm{ml}$ of this blend onto each of $40 \mathrm{~V} 8$ agar plates amended with $0.25 \mathrm{~g}$ of streptomycin sulfate per liter. Cultures were grown for 6 to 7 days at room temperature with approximately $12 \mathrm{~h}$ of diurnal fluorescent light. Inoculum was prepared by blending cultures in deionized water. The resulting propagule suspension was strained through two layers of cheesecloth, further diluted with water, and amended with Tween 20 surfactant (polyoxyethylene 20 -sorbitan monolaurate) at a rate of $0.2 \mathrm{ml} / \mathrm{liter}$. Approximately 12.7 liters of inoculum suspension were applied per 1,000 plants. Inoculum suspension was applied to whorls and the 
underside of leaves with backpack sprayers (Solo model 425; Solo Inc., Newport News, VA) equipped with cone nozzles. Plants were inoculated 12 times from 4 June to 16 July in 1997 and 6 times from 4 June to 29 June in 1998. Inoculum spore concentrations averaged $1.4 \times 10^{3}$ spores per $\mathrm{ml}$ in 1997 and $3.9 \times 10^{3}$ spores per $\mathrm{ml}$ in 1998.

Phenotypic observations. Gray leaf spot disease severity (percent leaf area affected) was visually estimated on a 0 to $100 \%$ scale in $5 \%$ increments. Individual plants were rated and row means were calculated for further statistical analysis. The earlier of two ratings was performed at about two weeks after flowering, and the later rating was performed approximately two to three weeks later. In 1997, plots were rated at Urbana on 21 through 23 August and 9 through 11 September. In 1998, plots were rated at Urbana on 29 through 31 July and 19 through 20 August, and at Andrews on 12 through 13 August and 28 through 29 August. Plant and ear height of the $\mathrm{P}_{1}, \mathrm{P}_{2}, \mathrm{~F}_{1}$ and $301 \mathrm{BCP}_{1} \mathrm{~S}_{1}$ families was recorded on 25 August 1997 and 1 September 1998. A measuring stick was placed in the center of each row, and row means were visually estimated. Plant height was estimated from the soil line to the tip of the tassel, and ear height was estimated from the soil line to the upper ear node. A ratio between plant and ear height was calculated to detect changes in ear height relative to overall plant height. This ratio, the percentage of main stem to the ear (PME), was calculated using the formula: $\mathrm{e} / \mathrm{p} \times 100$; where $\mathrm{e}=\mathrm{ear}$ height in $\mathrm{cm}$ and $\mathrm{p}=$ plant height in $\mathrm{cm}$.

Phenotypic data analyses. Analyses of all phenotypic data were performed with Statistical Analysis System (SAS) software (SAS Institute Inc., Cary, NC). The general linear models procedure (GLM) was used to analyze the effects of environments, rating periods, families, and the interactions between these factors. Environment and block effects were considered to be random, while the family effects were considered fixed. Rating periods for GLS disease severity were analyzed as a repeated measure using the REPEATED option under PROC GLM. The TEST option was used to correct for nonstandard structure in expected mean squares and to select appropriate error terms. Estimates of the variance components associated with all model terms were calculated using the PROC MIXED option (SAS

TABLE 1. Restriction enzyme and probe combinations used in gray leaf spot and height quantitative trait loci analysis of $301 \mathrm{BCP}_{1} \mathrm{~S}_{1}{ }^{a}$ families

\begin{tabular}{|c|c|c|c|}
\hline \multicolumn{4}{|c|}{ Enzyme and probes } \\
\hline BamHI & EcoRI & HindIII & HindIII \\
\hline AGRP83 & AGRP144 & AGRR87 & PHI20020 \\
\hline ASG1 & AGRR321 & AGRR167 & UMC7 \\
\hline ASG26 & ASG27 & ASG7 & UMC19 \\
\hline ASG59 & ASG31 & ASG8 & UMC34 \\
\hline ASG60 & ASG46 & ASG10 & UMC42 \\
\hline ASG66 & ASG53 & ASG18 & UMC46 \\
\hline BNL7.56 & BNL7.13 & ASG24 & UMC48 \\
\hline BNL14.07 & BNL8.23 & ASG32 & UMC64 \\
\hline CSU3 & BNL12.06 & ASG34 & UMC80 \\
\hline CSU381 & CSU31 & ASG41 & UMC90 \\
\hline CSU577 & CSU54 & ASG64 & UMC104 \\
\hline CSU600 & CSU61 & ASG71 & UMC108 \\
\hline NPI220 & CSU81 & ASG82 & UMC110 \\
\hline NPI268 & CSU164 & BNL5.09 & UMC111 \\
\hline UMC35 & CSU276 & BNL5.14 & UMC128 \\
\hline UMC36 & KSU5 & BNL6.06 & UMC131 \\
\hline UMC40 & NPI114 & BNL7.71 & UMC132 \\
\hline UMC43 & PHI6005 & BNL9.11 & UMC135 \\
\hline UMC53 & PHI20075 & BNL10.13 & UMC139 \\
\hline UMC58 & UMC5 & CSU25 & UMC156 \\
\hline UMC59 & UMC6 & CSU48 & UMC157 \\
\hline UMC89 & UMC67 & CSU440 & UMC159 \\
\hline UMC105 & UMC76 & CSU585 & \\
\hline UMC120 & UMC102 & NPI373 & \\
\hline UMC130 & UMC113 & NPI386 & \\
\hline UMC137 & UMC116 & PHI10017 & \\
\hline
\end{tabular}

${ }^{\mathrm{a}}$ Backcross to parent one, selfed one.
System for Mixed Models. SAS Institute Inc.). Heritabilities $\left(h^{2}\right)$ of GLS resistance and PME were calculated as a ratio of the estimated genetic variance to the phenotypic variance of a family mean using the formula outlined by Hallauer and Miranda (23):

$$
h^{2}=\sigma_{g}^{2} /\left(\sigma_{g}^{2}+\sigma_{g e}^{2} / e+\sigma^{2} / r^{*} e\right)
$$

Where $\mathrm{e}=$ the number of environments and $\mathrm{r}=$ the number of replications. Pearson correlations were calculated between mean disease ratings and height observations in each environment using the PROC CORR PEARSON option.

Random fragment length polymorphism assays and QTL analysis. Seed of the $\mathrm{P}_{1}, \mathrm{P}_{2}$ and $301 \mathrm{BCP}_{1} \mathrm{~S}_{1}$ families was sent to Biogenetic Services, Inc. (Brookings, SD) in December of 1997 for greenhouse planting and subsequent leaf-tissue DNA extraction. Eighty-six of the 100 probe-enzyme combinations screened for polymorphism were useful for construction of a random fragment length polymorphism (RFLP) linkage map (Table 1). Fourteen probes were unusable due to faint or smeared banding, the absence of parental bands, or excessive background noise. Linkage groups were detected and sorted by maximum-likelihood analysis with MAPMAKER 3.0 (32) at a $\log _{10}$ of the odds ratio (LOD) score of 4.0 (31).

The RFLP linkage map determined by MAPMAKER was further analyzed for the presence, locations, effects and interactions of QTL using the PLABQTL computer program (52). PLABQTL applies the composite interval mapping approach of Zeng (55), and has been used in previous studies to examine QTL associated with forage yield traits of European flint lines of corn $(35,37)$, common rust of corn $(36)$, and tassel traits of corn (6). Multiple regression methods of analysis were chosen for this study because they have been found to be more robust than maximum likelihood methods of analysis when residuals do not hold to the assumptions of a Gaussian distribution $(24,52)$. The model used for QTL detection was

$$
y_{i j}=\mu_{i}+\alpha_{i} x_{i}^{*}+\sum b_{k} x_{j k}+e_{i j}{ }^{k}
$$

where $y_{i j}=$ the phenotypic value of family $j$ in environment $i$; $\mu_{i}=$ the mean phenotypic trait value of families with the $\mathrm{P}_{1}$ genotype (qq) at a putative QTL in environment $i ; \alpha_{i}=$ the average effect of substituting an allele from $\mathrm{P}_{1}$ with an allele from $\mathrm{P}_{2}$ at the putative QTL under consideration in environment $i ; x_{i}^{*}=$ values 0 or 0.5 designating genotypes qq or qQ respectively. This value represents the conditional expectation of a putative QTL in environment $i$ based on probabilities calculated from flanking marker

TABLE 2. Simple statistics of location/year/rating period combinations for the $\mathrm{P}_{1}^{\mathrm{a}}, \mathrm{P}_{2}{ }^{\mathrm{b}}, \mathrm{F}_{1}$, and $301 \mathrm{BCP}_{1} \mathrm{~S}_{1}{ }^{\mathrm{c}}$ families

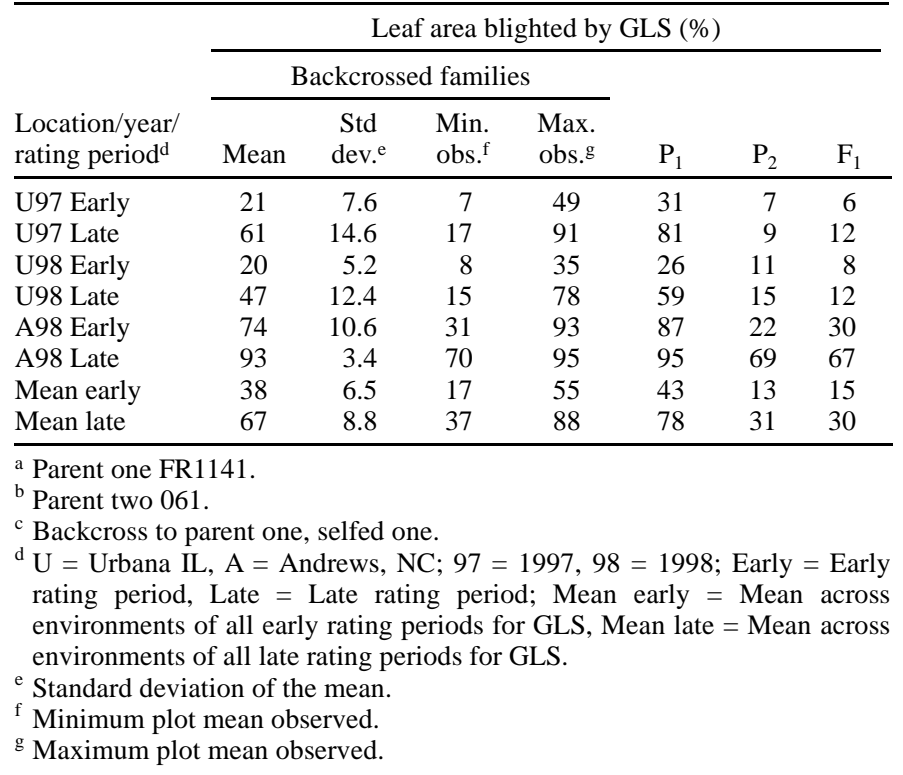


genotypes and associated phenotypic values (28); $b_{k}=$ the partial regression coefficient of phenotype on selected marker $k ; \mathrm{x}_{j k}=$ values 0 or 0.5 designating the genotype $\left(\mathrm{P}_{1}\right.$ or heterozygous respectively) of family $j$ at marker $k$; and $e_{i j}=$ residual error associated with family $j$ in environment $i$. Notation for this formula was adapted from the previous work of Lübberstedt et al. (35).

Cofactors employed for composite interval mapping within and across environments were selected via stepwise multiple regression (20) using the COV SELECTED option. LOD plot curves were generated from 2 centimorgan $(\mathrm{cM})$ interval scanning of all linkage groups. Putative QTL were declared significant when the maximal position of a LOD curve met or exceeded a score of 3.88. The high LOD threshold was chosen to hold the analysis to an experiment-wise error rate of $P \leq 0.01$ (comparisonwise $P \leq 0.000133$ ) as determined by $F$ statistic transformations calculated by PLABQTL and outlined by Haley and Knott (24). Multiple QTL discovered within the same $20 \mathrm{cM}$ interval were considered to have accounted for the same genomic region. The proportion of the phenotypic variance explained by each QTL was estimated with the square of the partial correlation coefficient $\left(\mathrm{R}^{2}\right)$. The ENV option was employed to analyze QTL $\times$ environment interactions at the $P>0.05$ and $P>0.01$ significance levels. Digenic epistatic effects between QTL were initially examined via the SMODEL command, however this command was later dropped and a model without epistatic interactions was chosen for the final analysis.

\section{RESULTS}

Disease evaluation. Severe GLS was observed by anthesis in all three environments tested (Table 2). Disease progression at Urbana, IL in 1997 was slow in the early season due to abnormally dry weather conditions. Mid- to late-season rains however, later created conditions that were favorable for rapid GLS development. Weather conditions in 1998 at Urbana, IL and Andrews, NC were ideal for GLS development. Early season high humidity, morning fogs and intermittent rains were followed by late season high temperatures.

Plot means for GLS ratings of the $301 \mathrm{BCP}_{1} \mathrm{~S}_{1}$ families formed a continuous distribution (Fig. 1). Due to the large number of families with intermediate levels of resistance, Shapiro-Wilks' test of normality indicated that plot means did not hold to the assumptions of a Gaussian distribution (45). Pearson correlations between all environment/rating period combinations ranged from 0.33 to 0.92 $(P \leq 0.01)$. Higher correlations were observed between early and late ratings taken within the same year than between ratings taken during different years (Table 3). Early and late disease ratings averaged across environments were highly correlated at $0.90(P \leq$ $0.01)$. Highly significant differences $(P \leq 0.01)$ in GLS severity were observed between environments, rating periods, families, and their interactions as calculated by SAS (Table 4). Heritability of GLS resistance was estimated to be 0.73 .

RFLP analysis. All ten of the corn chromosomes were represented in a 2007 cM RFLP linkage map constructed with MAPMAKER. Approximately 13\% of the total marker data were missing (across all probes used in the analysis) due to faint or smeared banding, the absence of parental bands or excessive background noise. The average interval length between probes was $26.4 \mathrm{cM}$, with approximately $86 \%$ of the genome within $20 \mathrm{cM}$ of the nearest marker. Twenty-four markers were found which significantly deviated from the expected 1:1 segregation of homozygous to heterozygous genotypes. Seventeen of these markers had lower than expected values for the homozygous FR1141 genotype.

QTL analysis. Digenic epistatic effects were originally tested in models for disease resistance and PME, however, epistatic effects were not significantly $(P>0.05)$ associated with these traits when included in final multiple regression models with selected QTL. For this reason, epistatic effects were not included in further analyses.

Four QTL located near probes CSU3, UMC139, ASG71, and ASG34 on chromosomes 1, 2, 5, and 7 respectively were significantly associated with GLS resistance across all environments and rating periods. A fifth QTL was identified on chromosome 5 in the region bounded by probes UMC43 and BNL7.71. The estimated position of this QTL shifted across rating periods by approximately $2 \mathrm{cM}$, and therefore significant associations between the QTL and individual markers shifted from probe UMC43 in the early rating period to probe UMC40 in the late rating period. Because the entire region which bounds this activity is less than $20 \mathrm{cM}$ in length, the association to GLS resistance identified here was considered to be one QTL. The five regions identified are associated with additive effects on
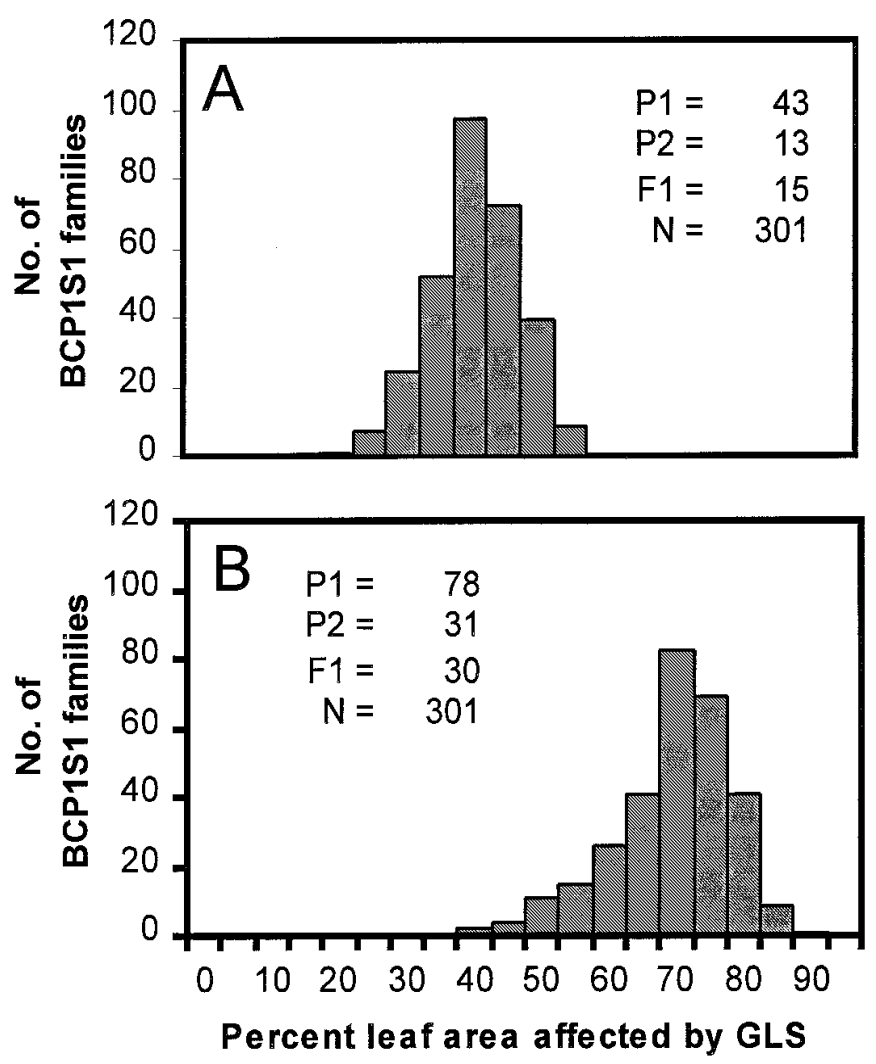

Fig. 1. Frequency distributions of gray leaf spot means across environments in A, early, and B, late rating periods. P1 is the susceptible parent FR1141. $\mathrm{P} 2$ is the resistant parent 061 . F1 is the cross between parents. $\mathrm{N}$ is the number of $\mathrm{BCP}_{1} \mathrm{~S}_{1}$ families evaluated in each environment.

TABLE 3. Pearson correlation coefficients for all gray leaf spot disease ratings of $301 \mathrm{BCP}_{1} \mathrm{~S}_{1}$ a families

\begin{tabular}{lccccccc}
\hline Parameter & $\begin{array}{c}\text { U97 } \\
\text { Late }\end{array}$ & $\begin{array}{c}\text { U98 } \\
\text { Early }\end{array}$ & $\begin{array}{c}\text { U98 } \\
\text { Late }\end{array}$ & $\begin{array}{c}\text { A98 } \\
\text { Early }\end{array}$ & $\begin{array}{c}\text { A98 } \\
\text { Late }\end{array}$ & $\begin{array}{c}\text { Mean } \\
\text { early }\end{array}$ & $\begin{array}{c}\text { Mean } \\
\text { late }\end{array}$ \\
\hline U97 Early & $0.79^{* * c}$ & $0.33^{* *}$ & $0.44^{* *}$ & $0.56^{* *}$ & $0.44^{* *}$ & $0.79^{* *}$ & $0.69^{* *}$ \\
U97 Late & $0.47^{* *}$ & $0.60^{* *}$ & $0.71^{* *}$ & $0.61^{* *}$ & $0.82^{* *}$ & $0.91^{* *}$ \\
U98 Early & & & $0.84^{* *}$ & $0.57^{* *}$ & $0.50^{* *}$ & $0.71^{* *}$ & $0.71^{* *}$ \\
U98 Late & & & & $0.66^{* *}$ & $0.58^{* *}$ & $0.76^{* *}$ & $0.87^{* *}$ \\
A98 Early & & & & & $0.80^{* *}$ & $0.92^{* *}$ & $0.80^{* *}$ \\
A98 Late & & & & & & $0.75^{* *}$ & $0.74^{* *}$ \\
Mean early & & & & & & & $0.90^{* *}$ \\
\hline
\end{tabular}

${ }^{\text {a }}$ Backcross to the susceptible parent selfed.

${ }^{\mathrm{b}} \mathrm{U}=$ Urbana, IL, A = Andrews, NC; 97 = 1997, 98 = 1998; Early = Early rating period for gray leaf spot $(\mathrm{GLS})$, Late $=$ Late rating period for GLS; Mean early = Mean across environments of all early rating periods for GLS, Mean late $=$ Mean across environments of all late rating periods for GLS.

c ** Denotes significance at $P \leq 0.01$. 
phenotype (alleles donated by the resistant parent contribute to increased disease resistance), and account for between 51.0 and $58.7 \%$ of the phenotypic variation (Table 5). Early disease development appears to be additionally affected by QTL near ASG10, NPI373 and UMC111 (chromosomes 3, 6, and 7 respectively); whereas later ratings indicate additional significant effects near probes UMC102, AGRR321, and UMC89 (chromosomes 3, 4, and 8 respectively). Approximately 58 and $52 \%$ of the genetic variance was accounted for by QTL associated with GLS severity during the early and late rating periods, respectively. Although genotype by environment $(G \times E)$ interactions were significant for most of the QTL in the final model, the sign of the regression coefficients for individual QTL did not change across environments.

TABLE 4. Repeated measures analysis of variance for $301 \mathrm{BCP}_{1} \mathrm{~S}_{1}{ }^{a}$ families evaluated for gray leaf spot severity

\begin{tabular}{lrccc}
\hline Source of variation & \multicolumn{1}{c}{$\mathrm{df}^{\mathrm{b}}$} & Mean square & $F$ value & $P>F^{\mathrm{c}}$ \\
\hline Env $^{\mathrm{d}}$ & 2 & $862,865^{* * \mathrm{e}}$ & 719.1 & 0.0001 \\
Blocks(env) $^{\mathrm{f}}$ & 3 & 1,200 & $\ldots$ & $\ldots$ \\
Families $^{\mathrm{f}}$ & 300 & $669^{* *}$ & 5.4 & 0.0001 \\
Families $\times$ env & 600 & $123^{* *}$ & 2.3 & 0.0001 \\
Residual error & 900 & 55 & & \\
\hline
\end{tabular}

a Backcross to parent one, selfed one. Evaluated in three environments over two rating periods.

${ }^{\mathrm{b}}$ Degrees of freedom.

${ }^{c}$ Significant probability associated with $F$ value.

${ }^{\mathrm{d}}$ Environments tested against the error term blocks(env).

e ** Denotes significance at $P>0.01$.

${ }^{\mathrm{f}}$ Families tested against the error term families $\times$ environment.
Four QTL near probes UMC76 and CSU3 on chromosome 1, BNL5.14 on chromosome 3, and CSU31 on chromosome 8 were significantly associated with ear height relative to plant height (PME) in both environments tested (Table 5). Alleles donated by the resistant parent at regions near probes UMC76, CSU3, and CSU31 increased PME by approximately $1 \%$. Alleles donated by the resistant parent at the region identified near BNL5.14 decreased PME by approximately $2 \%$. These four QTL accounted for approximately $35 \%$ of the phenotypic variation and approximately $64 \%$ of the genotypic variation among families. None of these QTL were significantly affected by environmental differences. Heritability of PME was estimated to be 0.44 .

\section{DISCUSSION}

Five QTL on chromosomes 1, 2, 5 and 7 were associated with relatively large, consistent effects on GLS resistance in multiple environments. Alleles contributing to increased GLS resistance at these five regions were donated by the resistant parent, 061. Many comparisons may be made between the resistant source material used in this experiment (061), and those used by Bubeck et al. (7) (NC250A and ADENT), and Saghai-Maroof et al. (44) (Va14) (Fig. 2), as each of these studies used B73, B73rhmlor a B73 recovery as the susceptible parent.

The QTL identified from 061 on chromosome 1 accounted for the largest amount of phenotypic variance at 20.9 to $23.3 \%$. This QTL may be the same region identified from Va14 as "QTL1," in which 35 to $56 \%$ of the variance was explained in three populations. A similar region of interest was identified from NC250A

TABLE 5. Selected quantitative trait loci (QTL; LOD $>$ 3.88) with QTL $\times$ environment interaction for height and gray leaf spot severity

\begin{tabular}{|c|c|c|c|c|c|c|c|c|c|c|c|c|c|c|}
\hline \multirow[b]{2}{*}{ Evaluation } & \multirow[b]{2}{*}{$\begin{array}{l}\text { Chromo- } \\
\text { some }\end{array}$} & \multirow[b]{2}{*}{$\begin{array}{c}\text { QTL } \\
\text { position on } \\
\text { chromosome }^{b}\end{array}$} & \multirow[b]{2}{*}{ LOD } & \multirow[b]{2}{*}{$\begin{array}{l}\text { Left } \\
\text { marker }\end{array}$} & \multirow[b]{2}{*}{$\begin{array}{l}\text { Right } \\
\text { marker }\end{array}$} & \multirow[b]{2}{*}{$\begin{array}{l}\text { Interval } \\
\text { between } \\
\text { markers }\end{array}$} & \multirow[b]{2}{*}{$\begin{array}{c}\text { Distance } \\
\text { of QTL } \\
\text { from left } \\
\text { marker }^{b}\end{array}$} & \multicolumn{4}{|c|}{$\begin{array}{l}\text { Regression coefficients in individual } \\
\text { environments and mean across environments }\end{array}$} & \multirow{2}{*}{\multicolumn{2}{|c|}{$\begin{array}{cc}\text { Phenotypic } \\
\text { variance } \\
\text { explained } \\
\mathrm{r}^{\mathrm{g}} \quad\left(\text { part } R^{2}\right)^{\mathrm{h}}\end{array}$}} & \multirow[b]{2}{*}{$\begin{array}{c}\text { Mean } \\
\text { square } \\
\text { QTL } \times \text { env }^{\mathrm{i}}\end{array}$} \\
\hline & & & & & & & & $e n v 1^{c}$ & env $2^{d}$ & env $3^{e}$ & $\begin{array}{c}\text { Mean } \\
\text { additive } \\
\text { effect }^{\mathrm{f}}\end{array}$ & & & \\
\hline \multirow{10}{*}{$\begin{array}{l}\text { Early rating } \\
\text { for GLS }\end{array}$} & & & & & & & & & & & & & & \\
\hline & 1 & 130 & 20.63 & CSU3 & CSU61 & 16.4 & 14 & -1 & -6 & -9 & $-5^{*} *^{\mathrm{i}}$ & 0.6 & 23.3 & $1,014^{* *}$ \\
\hline & 2 & 116 & 4.66 & UMC139 & UMC137 & 53.0 & 25 & -4 & -4 & -6 & $-4 * *$ & 0.8 & 10 & 75 \\
\hline & 3 & 222 & 5.58 & ASG10 & CSU25 & 69.0 & 52 & -3 & -2 & -5 & $-4 * *$ & 0.7 & 7.1 & 37 \\
\hline & 5 & 84 & 7.70 & UMC40 & BNL7.71 & 6.5 & 1 & -1 & -1 & -4 & $-2 * *$ & 0.6 & 4.2 & $464 * *$ \\
\hline & 5 & 140 & 9.25 & ASG71 & CSU440 & 16.2 & 15 & -4 & -1 & -5 & $-3 * *$ & 0.6 & 8.3 & $522 * *$ \\
\hline & 6 & 68 & 4.69 & NPI373 & UMC46 & 46.1 & 9 & -2 & -1 & -4 & $-2 * *$ & 0.7 & 4.5 & $103 * *$ \\
\hline & 7 & 48 & 6.74 & ASG34 & UMC116 & 27.5 & 8 & -3 & -1 & -5 & $-3 * *$ & 0.7 & 5.2 & $416^{* *}$ \\
\hline & 7 & 100 & 4.79 & UMC111 & ASG32 & 22.0 & 12 & -3 & -1 & -4 & $-3 * *$ & 0.7 & 5.2 & $415^{* *}$ \\
\hline & 1 & 130 & 18.58 & CSU3 & CSU61 & 16.4 & 14 & -6 & -13 & -2 & $-7 * *$ & 0.8 & 20.9 & $1,688 * *$ \\
\hline \multirow{8}{*}{$\begin{array}{l}\text { Late rating } \\
\text { for GLS }\end{array}$} & & & & & & & & & & & & & & \\
\hline & 2 & 108 & 6.91 & UMC139 & UMC137 & 53.0 & 17 & -9 & -10 & -2 & $-7 * *$ & 1.0 & 14.1 & $772 * *$ \\
\hline & 3 & 128 & 4.11 & UMC102 & BNL5.14 & 28.6 & 25 & 3 & 4 & 0 & $2 * *$ & 0.8 & 2.5 & 114 \\
\hline & 4 & 64 & 3.89 & AGRR321 & UMC 156 & 20.4 & 19 & 0 & 6 & 0 & $2 * *$ & 0.8 & 2.4 & $663 * *$ \\
\hline & 5 & 82 & 7.53 & UMC43 & UMC40 & 12.6 & 11 & -3 & -3 & -1 & $-2 * *$ & 0.8 & 2.7 & $507 * *$ \\
\hline & 5 & 140 & 12.01 & ASG71 & CSU440 & 16.2 & 15 & -9 & -4 & -1 & $-5^{* *}$ & 0.8 & 9.7 & $1,142 * *$ \\
\hline & 7 & 50 & 6.25 & ASG34 & UMC116 & 27.5 & 10 & -11 & -4 & -2 & $-6^{* *}$ & 0.9 & 11.3 & $1,516^{* * *}$ \\
\hline & 8 & 150 & 4.75 & UMC89 & CSU31 & 8.1 & 10 & -6 & -3 & -0 & $-3 * *$ & 0.8 & 5.6 & $666^{* *}$ \\
\hline \multirow[t]{4}{*}{ PME } & 1 & 66 & 4.78 & UMC76 & ASG26 & 14.9 & 2 & 1 & 1 & & $1 * *$ & 0.3 & 4.8 & 16 \\
\hline & 1 & 128 & 11.08 & CSU3 & CSU61 & 16.4 & 12 & 2 & 2 & & $2 * *$ & 0.3 & 13.8 & 26 \\
\hline & 3 & 134 & 7.99 & BNL5.14 & ASG10 & 38.2 & 2 & -2 & -1 & & $-2 * *$ & 0.3 & 12.9 & 22 \\
\hline & 8 & 154 & 5.25 & CSU31 & UMC48 & 8.1 & 4 & 1 & 1 & & $1 * *$ & 0.3 & 3.7 & 8 \\
\hline
\end{tabular}

${ }^{a}$ Likelihood odds ratio.

b In centimorgans.

${ }^{\mathrm{c}}$ Env01 = Urbana, 1997.

${ }^{\mathrm{d}}$ Env02 = Urbana, 1998.

e Env03 = Andrews, 1998.

${ }^{\mathrm{f}}$ Mean additive effect $=$ average of additive effects across three environments.

$\mathrm{g}$ Standard error of the mean additive effect.

${ }^{\mathrm{h}}$ Square of the partial correlation coefficient.

${ }^{i}$ Mean square of QTL by environment interaction.

j *** Denotes significance at $P>0.05$ and $P>0.01$, respectively. 
and ADENT on chromosome1 near probe PHI200682. Although the location of PHI200682 compares closely to QTL identified from Va14 and 061, the association of this region from NC250A and ADENT with GLS resistance was not consistent across environments.
One region on the long arm of chromosome 2 near probe UMC131 was identified from NC250A and ADENT as being consistently associated with GLS resistance across environments. A similar maturity- and environment-independent QTL on

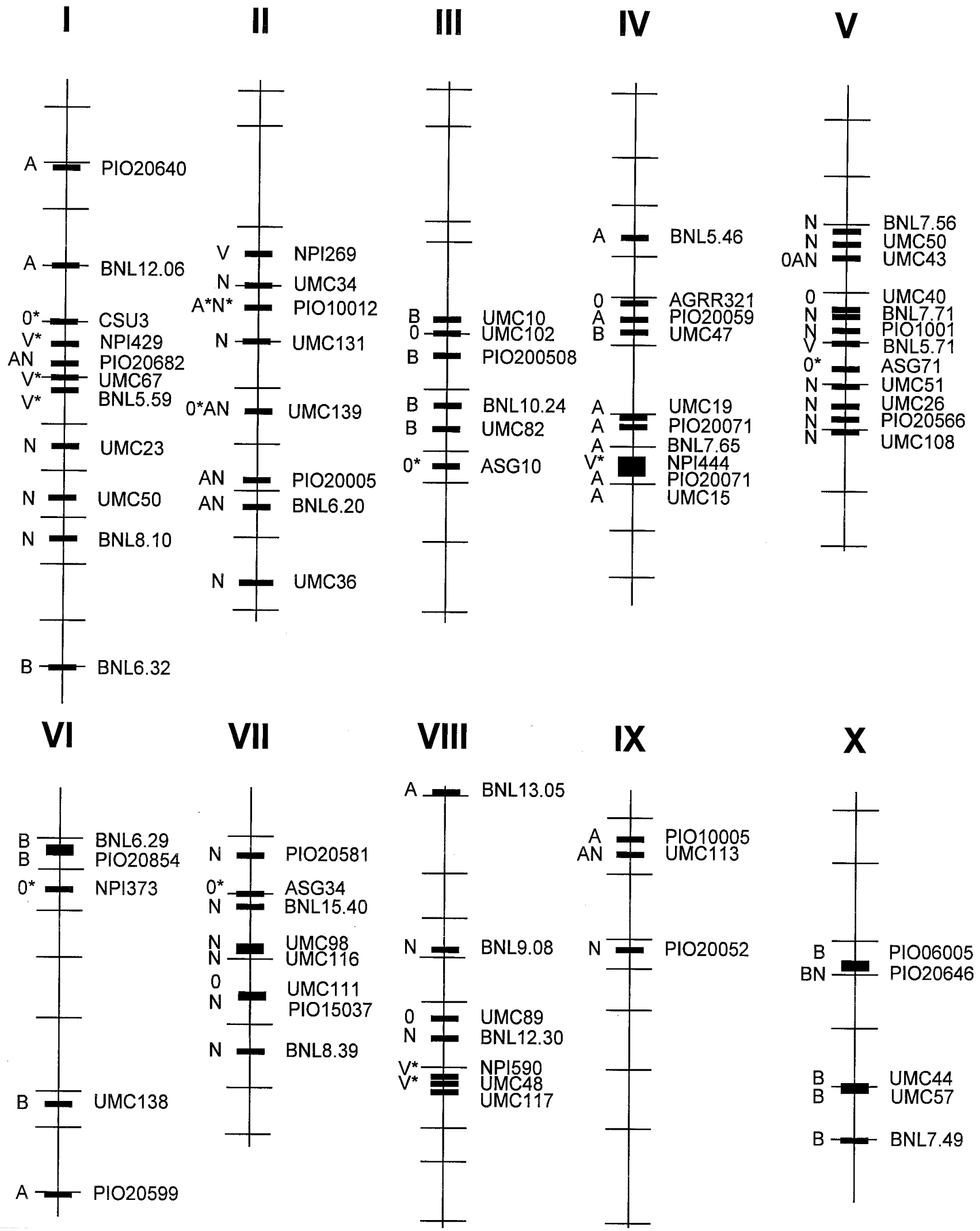

Fig. 2. Approximate map locations of probes significantly associated with gray leaf spot in three QTL studies. Hatch marks indicate bin (18) locations. $*=$ probes identified consistently across populations and environments in individual studies. $0=$ marker alleles identified from 061 in a population derived from the cross of FR1141 x 061. A = marker alleles identified from ADENT in populations derived from the cross of ADENT x B73rhm1. $\mathrm{N}=$ marker alleles identified from NC250A in populations derived from the cross of NC250A x B73 or B73rhm1.B = marker alleles identified from B73 or B73rhm1 in populations derived from the cross of either ADENT or NC250A with B73 or B73rhml. 
chromosome 2 was identified from 061, however, our findings associate this effect with probe UMC139. NC250A and ADENT also were found to contribute resistance associated with probe UMC139, however the effect was environment-dependent and appeared to influence maturity. Despite the disparity of a maturity affect, the close proximity of probes UMC131 and UMC139 (within $20 \mathrm{cM}$ ) suggests that 061, NC250A and ADENT may share an analogous genomic region on chromosome 2 .

Resistance to GLS has been associated with regions of chromosome 5 from Va14, NC250A and ADENT. In each of these studies, the regions of interest were significant in only a limited number of environments.

Two marker-associated effects were identified on chromosome 5 from 061. The first, located near probes UMC43 and UMC40, accounted for 2.7 and $4.2 \%$ of the phenotypic variation in early and late rating periods, respectively. The second, associated with probe ASG71, accounted for 8.3 and $9.7 \%$ of the variation in early and late rating periods. These regions are similar to those identified from Va14, NC250A and ADENT (Fig. 2), indicating that, with the strict LOD threshold used in this experiment, their significance on chromosome 5 is probably not the result of type I error.

The chromosome 7 QTL identified from 061 accounted for 5.2 and $11.3 \%$ of the phenotypic variation in early and late rating periods. A similar region near probe PIO150037 was identified in two populations derived from NC250A; however, no markerassociated effect was noted in the ADENT population of the same study. It is possible that 061 and $\mathrm{NC} 250 \mathrm{~A}$ share an analogous genomic region on chromosome 7 , and if so, share genes for resistance in this region that are different than those described from Va14 and ADENT.

In addition to the five environment- and maturity-independent QTL described earlier in this paper, this study identifies three QTL with associations to GLS severity only during early ratings, and three QTL with associations to GLS severity only during later ratings (Table 5). This is not surprising, as associations have been reported between GLS severity and inbred or hybrid maturity $(7,11,22,38,43,44)$. Increased GLS severity was associated with alleles from 061 for two of the three QTL identified only during the later rating. This suggests that alleles donated by the resistant parent at these two regions may either favor disease development in the late season, or contribute to early maturity and early senescence of the host. If the second hypothesis is correct, then early senescence of families with these QTL may mask beneficial effects associated with QTL identified from earlier ratings. Further, early host senescence may also contribute to excessive estimates of GLS severity during the late rating. Additional research with inbred 061 may be needed to determine the actual phenotypic effects associated with these QTL, and to separate the effects of early senescence and maturity from GLS severity.

A portion of this research was to determine if QTL associated with GLS resistance were in close proximity to QTL associated with ear height relative to plant height. Supplementary markerassociated information such as this should aid in recovery of elite inbreds, while minimizing deleterious linkage or pleiotropic effects. In this study, ear height relative to plant height was not significantly $(P>0.05)$ correlated with GLS severity in four of the twelve environment/rating period combinations of 1997 and 1998 (8). Significant correlations between heigher ear height and GLS resistance in the eight remaining environment/rating periods were low (8). This suggests that a very small number of QTL commonly influence both GLS resistance and ear height in the cross of $061 \times$ FR1141. Alleles from the resistant parent were associated with both ear height relative to plant height and GLS resistance at only one region near CSU3 on chromosome 1.

One challenge is to identify and use polygenes that perform consistently in multiple environments. Although genotype by environment interactions were significant for most of the QTL identified for resistance in this study, no changes were observed in the sign of additive effects between environments. This finding is consistent with that of Bubeck et al. (7) and would suggest that changes in magnitude, or noncrossover interactions, are associated with major QTL for GLS resistance. Another challenge is directing genes of interest into elite germplasm while regulating effects from indirectly selected traits. This study identifies five QTL which control a high level of resistance to GLS irrespective of environment and maturity stage of the host. The QTL that conferred the largest amount of resistance to GLS also was associated with variation in ear height relative to plant height, therefore, plant and ear heights should be noted when selecting for this region in crosses with lines known for undesirable ear height.

\section{ACKNOWLEDGMENTS}

Support provided by The Illinois Council on Food and Agricultural Research. We thank Pioneer Hi-bred International, Inc. for planting plots and providing field space in Andrews, NC; Illinois Foundation Seeds, Inc. for plant materials used in this study; and Dr. H. F. Utz, University of Hohenheim, Germany for assistance with PLABQTL. Additional thanks to S. Coates, A. Forbes, A. Kraja, R. Rozzi, D. Severns, S. Sipp, C. Smyth and J. Wong for technical assistance.

\section{LITERATURE CITED}

1. Abler, B. S. B., Edwards, M. D., and Stuber, C. W. 1991. Isoenzymatic identification of quantitative trait loci in crosses of elite maize inbreds. Crop Sci. 31:267-274.

2. Ayers, J. E., Johnson, Jr., M. W., and Hill, Jr., R. R. 1984. Identifying resistance to gray leaf spot. Pages 157-175 in: Proc. Annu. Corn Sorghum Industry Res. Conf., 39th. D. Wilkinson and R. Brown, eds. Am. Seed Trade Assoc., Washington, DC.

3. Bair, W., and Ayers, J. E. 1986. Variability in isolates of Cercospora zeae-maydis. Phytopathology 72:810-815.

4. Beavis, W. D., Grant, D., Albertsen, M., and Fincher, R. 1991. Quantitative trait loci for plant height in four maize populations and their associations with qualitative genetic loci. Theor. Appl. Genet. 83:161145.

5. Berke, T. G., and Rocheford, T. R. 1995. Quantitative trait loci for flowering, plant and ear height, and kernel traits in maize. Crop. Sci. 35:1542-1549.

6. Berke, T. G., and Rocheford, T. R. 1999. Quantitative trait loci for tassel traits in maize. Crop Sci. 39:1439-1443.

7. Bubeck, D. M., Goodman, M. M., Beavis, W. D., and Grant, D. 1993. Quantitative trait loci controlling resistance to gray leaf spot in maize. Crop Sci. 33:838-847.

8. Clements, M. J. 1999. Quantitative trait loci associated with resistance to gray leaf spot of corn. M.S. thesis. University of Illinois, Urbana.

9. Coates, S. T. 1996. Inheritance of resistance to gray leaf spot of corn. $\mathrm{Ph}$.D. dissertation. University of Illinois at Urbana-Champaign.

10. Coates, S. T., and White, D. G. 1994. Sources of resistance to gray leaf spot of corn. Plant Dis. 78:1153-1155.

11. Coates, S. T., and White, D. G. 1998. Inheritance of resistance to gray leaf spot in crosses involving selected resistant inbred lines of corn. Phytopathology 88:972-982.

12. de Nazareno, N. R. X., Lipps, P. E., and Madden, L. V. 1993. Effect of levels of corn residue on the epidemiology of gray leaf spot of corn in Ohio. Plant Dis. 77:67-70.

13. Donahue, P. J., Stromberg, E. L., and Myers, S. L. 1991. Inheritance of reaction to gray leaf spot in a diallel cross of 14 maize inbreds. Crop Sci. 31:926-931.

14. Edwards, M. D., Helentjaris, T., Wright, S., and Stuber, C. W. 1992. Molecular-marker-facilitated investigation of quantitative trait loci in maize. 4. Analysis based on genome saturation with isozyme and restriction fragment length polymorphism markers. Theor. Appl. Genet. 83:765-774.

15. Elwinger, G. F., Johnson, M. W., Hill, R. R., and Ayers, J. E. 1990. Inheritance of resistance to gray leaf spot of corn. Crop Sci. 30:350-358.

16. Falconer, D. S. 1989. Introduction to Quantitative Genetics. 3rd ed. John Wiley \& Sons, Inc., New York.

17. Freund, R. J., and Wilson, W. J. 1997. Statistical Methods. Academic Press, New York.

18. Gardiner, J., Coe, Jr., E., Melia-Hancock, S., Hoisington, D. A., and Chao, S. 1993. Development of a core RFLP map in maize using an Immortalized-F2 population. Genetics 134:917-930.

19. Gerdes, J. T., Behr, C. F., Coors, J. G., and Tracy, W. F. 1993. 
Compilation of North American Maize Breeding Germplasm. Crop Science Society of America, Inc., Madison, WI.

20. Gevers, H. O., and Lake, J. K. 1994. Diallel cross analysis of resistance to gray leaf spot in maize. Plant Dis. 78:379-383.

21. Graham, M. J., Hawk, J. A., Carroll, R. B., Ayers, J. E., Lamkey, K. R., and Hallauer, A. R. 1993. Evaluation of Iowa Stiff Stalk Synthetic for resistance to gray leaf spot. Plant Dis. Rep. 63:515-518.

22. Gwinn, K. D., Stelzig, D. A., and Brooks, J. L. 1987. Effects of corn plant age and cultivar on resistance to Cercospora zeae-maydis and sensitivity to cercosporin. Plant Dis. 71:603-606.

23. Hallauer, A. R., and Miranda Fo, J. B. 1981. Quantitative genetics in maize breeding. Iowa State University Press, Ames.

24. Haley, C. S., and Knott, S. A. 1992. A simple regression method for mapping quantitative trait loci in line crosses using flanking markers. Heredity 69: 315-324

25. Hébert, Y., Barrière, Y., and Bertholeau, J. C. 1992. Root lodging resistance in forage maize: Genetic variability of root system and aerial part. Maydica 37:173-183.

26. Hilty, J. W., Hadden, C. H., and Garden, F. T. 1979. Response of maize hybrids and inbred lines to gray leaf spot disease and the effects on yield in Tennessee. Plant Dis. Rep. 63:515-518.

27. Huff, C. A., Ayers, J. E., and Hill, R. R. 1988. Inheritance of resistance in corn (Zeae mays) to gray leaf spot. Phytopathology 78:790-794.

28. Jansen, R. C., and Stam, P. 1994. High resolution of quantitative traits into multiple loci via interval mapping. Genetics 136:1447-1455.

29. Kato, A. 1997. Relationship between root lodging and five nondestructively-determined traits in maize. Maydica 43:65-74.

30. Koester, R. P., Sisco, P., and Stuber, C. 1993. Identification of quantitative trait loci controlling days to flowering and plant height in two near isogenic lines of maize. Crop Sci. 33:1209-1216.

31. Lander, E. S., and Botstein, D. 1989. Mapping mendelian factors underlying quantitative traits using RFLP linkage maps. Genetics 121:185199.

32. Lander, E. S., Green, P., Abrahamson, J., Barlow, A., Daly, M. J., Lincoln, S. E., and Nweburg, L. 1987. Mapmaker: An interactive computer package for constructing primary genetic linkage maps of experimental and natural populations. Genomics 1:174-181.

33. Latterell, F. M., and Rossi, A. E. 1983. Gray leaf spot of corn: A disease on the move. Plant Dis. 67:842-847.

34. Lipps, P. E., Thomison, P. R., and Pratt, R. C. 1996. Reaction of corn hybrids to gray leaf spot. Pages 163-189 in: Rep. Annu. Corn Sorghum Res. Conf., 51 st.

35. Lübberstedt, T., Klein, D., and Melchinger, A. E. 1998. Comparative quantitative trait loci mapping of partial resistance to Puccinia sorghi across four populations of European flint maize. Phytopathology 88: 1324-1329.

36. Lübberstedt, T., Melchinger, A. E., Fähr, S., Klein, D., Dally, A., and Westhoff, P. 1998. QTL mapping in testcrosses of flint lines of maize: III. Comparison across populations for forage traits. Crop Sci. 38:1278-1289.

37. Lübberstedt, T., Melchinger, A. E., Schön, C. C., Utz, H. F., and Klein, D. 1997. QTL mapping in testcrosses of European flint lines of maize: I. Comparison of different testers for farage yield traits. Crop Sci. 37:921-931.
38. Manh, N. Q. 1977. Inheritance of resistance to gray leaf spot in maize. M.S. thesis. Virginia Polytechnic Institute, Blacksburg, VA.

39. Melchinger, A. E., Geiger, H. H., and Schmidt, G. A. 1996. Vertical rootpull resistance and its relationship to root lodging and forage traits in early maturing European inbred lines and $F_{1}$ hybrids of maize. Maydica 31:335-348.

40. Payne, G. A., Duncan, H. E., and Adkins, C. R. 1987. Influence of tillage on development of gray leaf spot and number of airborne conidia of Cercospora zeae-maydis. Plant Dis. 71:329-332.

41. Payne, G. A., and Waldron, K. J. 1983. Overwintering and spore release of Cercospora zeae-maydis in corn debris in North Carolina. Plant Dis. 67:87-89.

42. Roane, C. W., Harrison, R. L., and Genter, C. F. 1974. Observations on gray leaf spot of maize in Virginia. Plant Dis. Rep. 58:456-459.

43. Rupe, J. C., Siegel, M. R., and Hartman, J. R. 1982. Influence of environment and plant maturity of gray leaf spot of corn caused by Cercospora zeae-maydis. Phytopathology 72:1587-1591.

44. Saghai Maroof, M. A., Yue, Y. G., Xiang, Z. X., Stromberg, E. L., and Rufener, G. K. 1996. Identification of QTL controlling resistance to gray leaf spot disease in maize. Theor. Appl. Genet. 93:539-546.

45. Steele, R. G. D., and Torrie, J. H. 1997. Principles and Procedures of Statistics. 3rd ed. McGraw-Hill Inc., New York.

46. Stromberg, E. L., and Flinchum, L. E. 1993. Evaluation of foliar fungicides for control of gray leaf spot disease of corn in Virginia, 1992. Fung. Nemat. Tests. 48:218.

47. Stuber, C. W., Lincoln, S. E., Wolff, D. W., Helentjaris, T., and Lander, E. S. 1992. Identification of genetic factors contributing to heterosis in a hybrid from two elite maize inbred lines using molecular markers. Genetics 132:823-839.

48. Tehon, L. R., and Daniels, E. 1925. Notes on the parasitic fungi of Illinois. Mycologia 17:248.

49. Thompson, D. L., Berquist, R. R., Payne, G. A., Bowman, D. T., and Goodman, M. M. 1987. Inheritance of resistance to gray leaf spot in maize. Crop Sci. 27:243-246.

50. Thorson, P. R., and Martinson, C. A. 1993. Development and survival of Cercospora zeae-maydis germlings in different relative-humidity environments. Phytopathology 83:153-157.

51. Ulrich, J. F., Hawk, J. A., and Carroll, R. B. 1990. Diallel analysis of maize inbreds for resistance to gray leaf spot. Crop Sci. 30:1198-1200.

52. Utz, H. F., and Melchinger, A. E. 1996. PLABQTL: A program for composite interval mapping of QTL.. In: J. Quant. Trait Loci. On-line publication: vol. 2, paper 1. Sponsored by the Crop Science Society of America.

53. Ward, J. M. J., Laing, M. D., and Rijkenberg, F. H. J. 1997. Frequency and timing of fungicide applications for the control of gray leaf spot in maize. Plant Dis. 81:41-48.

54. Zehr, B. E., Dudley, J. W., Chojecki, J., Saghai Maroof, M. A., and Mowers, R. P. 1992. Use of RFLP markers to search for alleles in a maize population for improvement of an elite hybrid. Theor. Appl. Genet. 83:903-911.

55. Zeng, Z. B. 1994. Precision mapping of quantitative trait loci. Genetics 136:1457-146. 